\title{
RESVERATROL: MORE THAN A PHYTOCHEMICAL
}

\author{
Parichehr Hassanzadeh $^{\mathbf{1}^{*}}$, Fatemeh Atyabi ${ }^{1,2}$, and Rassoul Dinarvand ${ }^{\mathbf{1 , 2}}$ \\ ${ }^{I}$ Nanotechnology Research Center, Faculty of Pharmacy, Tehran University of Medical Sciences, Tehran, \\ Iran, ${ }^{2}$ Department of Pharmaceutics, Faculty of Pharmacy, Tehran University of Medical Sciences, \\ Teheran, Iran
}

In recent years, alternative and complementary medicine including the plant-based drugs with antioxidant and neuroptotective effects has attracted a growing interest. Resveratrol, a polyphenolic compound which is found in various plant species, has emerged as a promising nutraceutical with therapeutic potentials in neuropsychiatric, cardiometabolic and cancer diseases, also aging. The abundance of research providing promising findings about the multi-spectrum therapeutic applications of resveratrol and its encouraging potential to treat or prevent chronic and age-related disorders has raised a considerable number of clinical trials. Recently, resveratrol is implicated the biology of nerve growth factor (NGF), a critical player in the maintenance of neuronal growth and function. Furthermore, resveratrol affects the endocannabinoid signalling (eCBs) which exerts modulatory effects in the survival signalling pathways, neural plasticity, and a variety of neuroinflammatory and neurodegenerative processes. The therapeutic effects of this ubiquitous signalling system in Alzheimer's disease, epilepsy, multiple sclerosis, mood and movement disorders, spinal cord injury, and stroke have been well-documented. In the present review, the implication of NGF and eCBs in the mechanism of action of resveratrol, that may be of therapeutic significance in neurological and non-neurological disorders, is highlighted. Biomed Rev 2015; 26: 13-21.

Key words: polyphenol, nerve growth factor, endocannabinoid system, neurological disorders

\section{INTRODUCTION}

Over the last few decades, studies on the health benefits of herbs have shown the ability of plants to synthesize a variety of compounds which interact with biological pathways (1). Resveratrol (3,5,4'-trihydroxy-trans-stilbene; $\mathrm{C}_{14} \mathrm{H}_{12} \mathrm{O}_{3}$, Fig. 1), a polyphenolic compound which is found in various plant species, has shown a wide range of pharmacological activities. This phytochemical (nutraceutical) inhibits the cyclooxygenase- 1 and 2 expression and nuclear factor- $\mathrm{KB}$ (NF$\mathrm{\kappa B})$ signalling and reduces the production of proinflammatory cytokines leading to the antiinflammatory and analgesic effects (2). Resveratrol via the induction of apoptosis of cancer cells and metabolism of carcinogens as well as

Received 5 December 2015, revised 12 December 2015, accepted 12 December 2015.

Correspondence to Dr Parichehr Hassanzadeh, Nanotechnology Research Center, Faculty of Pharmacy, Tehran University of Medical Sciences, Tehran, Iran Tel.: +98 21 66959095, Fax: +98 21 66581558, Cell phone: +98 9121887745

E-mail: p-hassanzadeh@razi.tums.ac.ir 


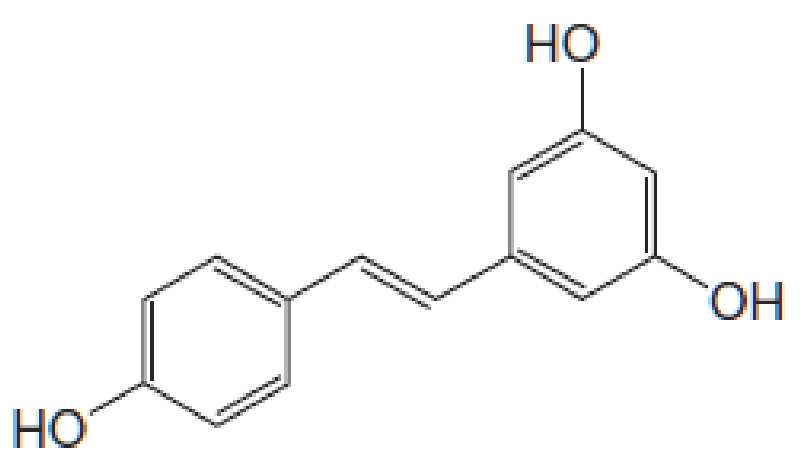

Figure 1. The chemical structure of resveratrol.

inhibition of cancer initiation and progression signalling exerts its anticancer effects (3). Since NF- $\kappa B$ signalling is a well-characterized target of cancers (4), inhibition of this signalling pathway by resveratrol (2) may be implicated in the anticarcinogenic effects of this natural polyphenol. Regarding the cardiometabolic protection, resveratrol inhibits inducible nitric oxide synthase (iNOS) and platelets aggregation, elevates high-density lipoprotein, and reduces low-density lipoprotein, trigycerides, and reactive oxygen species (ROS) accumulation (5). Resveratrol acts against the oxidative stress via the up-regulation of antioxidant enzymes synthesis and enhancement of the anti-oxidant capacity, free radical scavenging activity, as well as the inhibition of lipid peroxidation, and regeneration of $\alpha$-tocopherol (6). Obesity, because of its complexity and multi-factorial nature, has remained as a challenging medical problem (7). Resveratrol by inhibition of the adipogenesis and down-regulation of lipogenic genes, and enhancement of fat oxidation has shown promising anti-obesity effects (8). In type 2 diabetes mellitus, resveratrol, by activating sirtuin 1 , elevates the glucose uptake by muscles and modulates the $\beta$-cells insulin secretion (9). Regarding the neuroprotective properties of resveratrol, there are reports indicating its inhibitory effects against the memory deterioration, neuroinflammation, and oxidative stress in the hippocampus. Resveratrol improves the sensorimotor function, modulates the cholinergic neurotransmission, and prevents the oxidative damage of astroglial cells and cognitive decline. This natural compound downregulates the glutamateinduced extracellular signal-regulated kinase activation and interleukin-1 $\beta$ (IL- $\beta$ ) expression in the hippocampus (10-12). Study on the primary cortical neuron cultures has revealed that resveratrol through the inhibition of intracellular calcium increase and production of ROS exerts the protective effect against N-Methyl-D-aspartate-induced neuronal death (13). Furthermore, this natural polyphenol by antioxidant activities protects the hippocampal neurons against the NO-induced toxicity (14). In Alzheimer's disease, resveratrol has been shown to reduce the intracellular amyloid- $\beta$ peptides, NO production, iNOS expression, prostaglandin $\mathrm{E}_{2}$ accumulation, and NF- $\kappa B$ translocation (15). Resveratrol exhibits therapeutic potential in other neurodegenerative diseases such as Parkinson's disease (16) and amyotrophic lateral sclerosis (17) that may be due to its antioxidant and anti-inflammatory properties. This polyphenolic compound prevents the spinal cord and brain damage following the ischemia-reperfusion or traumatic injury (18).

In recent years, it has been shown that resveratrol exerts antidepressant effects via the modulation of hypothalamicpituitary (HPA) axis activity and oxidative-nitrosative stress and inhibition of the production of inflammatory cytokines (19-21). Based on an increasing evidence, neurotrophins, a protein family including the nerve growth factor (NGF), brain-derived neurotrophic factor (BDNF), neurotrophin 3 (NT-3), NT-4/5, and NT-6 act as the potential mediators of antidepressant responses $(22,23)$. Neurotrophins mediate their effects by the ligation of two major types of receptors: a high affinity tyrosine kinase (Trk) receptor and a low affinity pan-neurotrophin receptor ( $\left.\mathrm{p} 75^{\mathrm{NTR}}\right)$, thus trigger a number of cellular responses including the long-term trophic effects as well as the rapid chemotropic and morphogenetic actions on the developing neurons, synaptic transmission, and neuronal excitability (24-27). Neurotrophins are also implicated in the neuronal plasticity and exhibit neuroprotective effects that might be of therapeutic significance in the neuropsychiatric disorders (28). Indeed, dysfunction of the neurotrophin-related signalling mechanisms is involved in the pathogenesis of a number of psychiatric disorders (23-26). The prototypical neurotrophin, NGF, which regulates the stress and cognitive function $(29,30)$ and mediates the action of a wide variety of psychotropic agents (31-35), along with the eCBs which regulates the neuroprotective processes (36), are implicated in the mechanism of action of resveratrol (37) that will be discussed herein.

\section{RESEVERATROL AND NGF}

Following the discovery of the first neurotrophin, NGF, by the Nobel Laureate Rita Levi-Montalcini (38), further 
studies showed that NGF as well as other neurotrophins (e.g. BDNF) affect the neuronal survival and differentiation, exerts a regulatory role in the memory and attention tasks, in neuroendocrine-immune interaction, and neurological disorders $(39,41)$. Because of its antioxidant, angiogenic and metabotrophic (including insulinotropic) properties, NGF is implicated in the molecular mechanisms of cardiometabolic diseases (41, 42, 48 and references therein), accelerates corneal and skin wound healing $(43,44)$ and plays a fundamental role in tissue engineering (45). Over the last decade, it has been suggested that electroconvulsive treatment or antidepressant drugs may act by increasing neurotrophin contents in the central nervous system (CNS). Based on the ability of NGF to induce the release of hypothalamic vasopressin which plays a crucial role in the formation of social bonding (46), it was suggested that NGF by modulating the neuroendocrine functions is implicated in the molecular mechanisms of emotions. In this respect, the involvement of NGF and BDNF in the pathogenesis of neuropsychiatric disorders $(39,41,47-49)$ and in the mechanisms of action of a wide range of psychotropic agents $(31-35,41,50)$ were reported. These findings might be of great significance in optimal management of neuropsychiatric disorders. Recently, the involvement of NGF in the mechanism of action of resveratrol has also been reported (37). The elevation of brain NGF levels following chronic treatment with resveratrol indicates that the neurotrophic effect is a slow-developing process. The sustained enhancement of NGF protein contents in the brain regions which regulate the emotional activity may be considered as a mechanism by which resveratrol exerts its therapeutic effects in the neuropsychiatric disorders. Since NGF exerts the stimulatory effect on the cell proliferation (51), therefore, the elevation of frontal cortex NGF following the chronic administration of resveratrol might be of therapeutic significance against the stress-induced reduction in cell proliferation in the frontal cortex (52).

Resveratrol also elevates NGF level in the hippocampus (37). It is noteworthy that NGF plays a pivotal role in learning, hippocampal plasticity, and neurogenesis $(29,30)$, and induces acetylcholine release in the hippocampus (49) leading to the improved cognitive performance. Therefore, resveratrol by enhancement of the hippocampal NGF may stimulate the hippocampal neurogenesis and improve the cognitive function. Moreover, this nutraceutical increases NGF contents in the olfactory bulb and amygdala (37). The critical role of NGF in the development, regeneration, and maintenance of the olfactory system of mammals has been well-documented (29, 30,53). NGF also facilitates the cholinergic neurotransmission between the amygdala and nucleus basalis (54) leading to the improvement of cognitive function. Altogether, it appears that elevation of brain NGF, also BDNF, contents constitutes a major part of the biochemical alterations induced by certain psychotropic agents $(31-35,41,50)$ including resveratrol (37).

\section{RESVERATROL AND THE ENDOCANNABINOID SIGNALING}

Over the last decade, the eCBs, a group of neuromodulatory lipids and their receptors which regulates the neuronal proliferation and maturation (55), synaptic plasticity (56), emotional reactivity (57), neurotensin neurotransmission (58-59) and neurotrophin signalling $(60,61)$, has emerged as a topic of great interest in neuroscience and pharmacology. The endocannabinoids, anandamide and 2-arachidonoylglycerol (2-AG), are produced on-demand by the lipid precursors in the neuronal cell membrane and activate two types of $\mathrm{G}$ protein-coupled receptors, cannabinoid $\mathrm{CB}_{1}$ and $\mathrm{CB}_{2}$, leading to a wide variety of pathological and physiological processes. The eCBs exerts neuroremodulatory action in various types of diseases (62). In this context, development of anandamide uptake blockers, cannabinoid receptor agonists, and selective inhibitors of endocannabinoid degradation has been the focus of intense research $(63,64)$. In transsynaptic neuronal changes due to the neurodegenerative processes (65), microglia-induced neurotoxicity, and cytotoxicity induced by the excitatory amino acids (66), the eCBs exerts protective effects (67). In general, the endocannabinoids exert their neuroprotective effects through a variety of mechanisms including the prevention of calcium influx, inhibition of NO and/or glutamate release, and activation of antioxidative mechanisms. Furthermore, activation of the $\mathrm{CB}_{1}$ receptors leads to the stimulation of phosphoinositide 3-kinase (PI3-K)/ AKT signalling pathway and promotion of the cell survival (68). According to the protective effects of the eCBs against the excitotoxic damage and neuronal insult $(58,67)$, this ubiquitous signalling system might be an emerging target for the therapeutic interventions against the neurological disorders. In Parkinson's disease (PD), the most prevalent neurodegenerative disorder affecting the basal ganglia, dopamine depletion results in a cascade of neurochemical events within the basal ganglia. Endocannabinoids and their synthesizing and degrading enzymes are abundantly found in the basal ganglia (69). Indeed, the striatal eCBs undergoes a profound neurophysiological alteration in order 
to restore the homeostasis within the basal ganglia (70). In Huntington's disease, the $\mathrm{CB}_{1}$ receptor agonists and inhibitors of eCB transport reduce the hyperkinesia associated with the disease (71). Stimulation of the $\mathrm{CB}_{1}$ or $\mathrm{CB}_{2}$ receptors results in the anti-inflammatory effects in multiple sclerosis (72). Furthermore, $\mathrm{CB}_{1}$ agonists promote the oligodendrocyte survival and mRNA expression of myelin protein (73) suggesting that the eCBs not only attenuates the symptoms of the disease, but also improves the function of oligodendrocytes that may be due to its antiinflammatory and neuroprotective effects. In the spinal cord injury, a cascade of cellular and molecular events which occur following the initial damage, is a main target for therapeutic interventions including the application of cannabinoids. In an animal model of the spinal cord injury, a significant increase of the $\mathrm{eCB}$ contents has been reported (74) suggesting that activation of the $\mathrm{eCBs}$ is a part of the neuroprotective response which is triggered following the injury.

In epilepsy, the imbalance between the inhibitory and excitatory neural circuits leads to the excitotoxicity and neuronal death (75-77). Based on the regulatory effects of the eCBs on the inhibitory and excitatory transmissions and the enhancement of the eCB contents in epilepsy (78), this ubiquitous signalling system may be a promising target for antiepileptic therapies. In ischemic stroke, recombinant tissue plasminogen activator improves the functional outcome in patients, however, it should be administered within a short period of time following the onset of symptoms. The nonpsychoactive component of cannabis, cannabidiol, has been shown to inhibit the voltage-sensitive $\mathrm{Ca}^{2+}$ channels leading to the reduction of excitotoxicity. Administration of cannabidiol $6 \mathrm{~h}$ after the cerebral ischemia has led to the neuroprotective effects. Furthermore, cannabidiol has preserved the regional cerebral blood flow and improved the motor coordination even at 3 days after the cerebral ischemia (79) indicating its longlasting preventive effects on the post-ischemic cerebrovascular events.

In Alzheimer's disease which is associated with neuroinflammation, neurodegeneration, and cognitive impairment (80), the eCBs is of therapeutic significance because of its anti-neuroinflammatory and neuroprotective effects $(62,81)$. In $\beta$-amyloid-induced neurotoxicity, the eCBs may exert protective effects through the inhibition of NO release and activation of mitogen-activated protein kinase pathway (82).

In amyotrophic lateral sclerosis, one of most the debilitating neurodegenerative disorder which is characterised by the degeneration of motor neurons, the eCBs has shown antiinflammatory and neuroprotective effects by the prevention of excitotoxic damage and preservation of glutamate homeostasis (83). Following the identification of the endocannabinoid binding sites in substantia gelatinosa, analgesic effects of the eCBs in both acute and chronic pain were identified $(84,85)$. The interaction between the opioid signalling and eCBs is also well-documented (86). Based on these multitarget bioactivities of the eCBs, its potential implication in the mechanism through which resveratrol regulates brain NGF contents has been investigated. It has been found that resveratrol affects brain NGF levels under the regulatory drive of $\mathrm{CB}_{1}$ receptors (37). Furthermore, the brain eCB contents are increased following the chronic treatment with resveratrol (37). It appears that the eCBs activation is required, at least in part, for the neuroprotective actions of resveratrol against the various types of neurological disorders.

Regarding the mood disorders, compounds which affect the eCBs function have been shown to regulate the monoaminemediated neurotransmission and activity of HPA axis (87). In the limbic brain regions where the neuronal activity is altered in depression (88), endocannabinoids are found at moderate to high levels (87). Indeed, the regulatory role of the eCB enhancers on mood (57), has opened a new line of research in antidepressant drug discovery and development of novel antidepressants. Cannabinoids may be beneficial against the anxiety-related disorders as the $\mathrm{CB}_{1}$ receptor antagonist, SR141716A, has been shown to induce anxiety-like responses (89). Chronic exposure to a wide range of psychotropic agents has resulted in a significant enhancement of eCB contents in the brain regions which regulate the synaptic plasticity and emotional behaviour $(32-35,37)$. In fact, the brain regional distribution of endocannabinoids following the administration of psychotropic agents represents the important role of the eCBs in the development of effective coping strategies to the emotional responses. As recently reported, four-week oncedaily injections of resveratrol results in a sustained elevation of annadamide and 2-AG contents in the brain regions implicated in the modulation of emotional behaviour and synaptic plasticity (37). This finding indicate the existence of an intrinsic $\mathrm{eCB}$ tone which is involved in the mechanism of action of resveratrol.

Following chronic administration of resveratrol, NGF and endocannabinoids have been increased in the same brain regions suggesting that the regulatory effect of resveratrol 
on brain NGF contents depends on the coordinated release of endocannabinoids. It appears that a balance between NGF and eCB signalling mediates the pharmacological effects of this natural polypheonlic compound. In addition to its intrinsic radical scavenging activity, resveratrol reduces the production of tumour necrosis factor- $\alpha, \mathrm{IL}-1 \beta, \mathrm{NF}-\mathrm{\kappa B}, \mathrm{NO}$, and the expression of iNOS gene. This natural polyphenol upregulates the activities of protein kinase $\mathrm{C}$ and heme oxygenase leading to the neuroprotective effects. In fact, multiple intracellular signalling pathways and molecular targets are involved in the mechanism of action of resveratrol (90). Involvement of the extracellular signal-regulated kinase cascade, noradrenaline and serotonin system, and HPA axis in the antidepressantlike effects of resveratrol has been previously demonstrated $(91,92)$. Based on the recent findings, the brain NGF and eCBs are also implicated in the mechanism of action of resveratrol. In this context, resveratrol by affecting NGF and eCBs might be of therapeutic significance in a wide variety of diseases which are associated with abnormal NGF or eCBs. Resveratrol enhances the brain NGF contents under the regulatory drive of $\mathrm{CB}_{1}$ receptors indicating the importance of the endogenous cannabinoid activity in the neurotrphic action of this nutraceutical.

In recent years, smart delivery of drugs, neurotrophins, and nutrients has been the focus of intense research. In nanotechnology-based approaches, nanoencapsulation of nutraceuticals, application of nanosensors and computational modelling have been the emerging topics (93-97). In this respect, designing the nanoformulations of resveratrol has led to the increased cellular uptake and improved bioavailability $(98,99)$. This may result in a better efficacy, reduced dose and potential side effects of this nutraceutical which has shown multi-spectrum therapeutic applications.

\section{CONCLUSION}

For over a decade, natural products with antioxidant, antiinflammatory, metabotrophic and neuroptotective effects have been the focus of intense research. Resveratrol, a naturally occurring polyphenolic compound, has shown multi-spectrum therapeutic applications. Besides its therapeutic potential in ischemia, cancer, diabetes, and cardiometabolic disorders, resveratrol has proved to be a promising therapeutic agent against the neurodegenerative disorders. In recent years, identification of the biological functions of the eCBs has resulted in a better understanding of the pathological processes which occur in the CNS.
Compounds which regulate the activity of the eCBs, have shown beneficial effects against various disorders in which the currently available drugs have shown limited efficacy. The eCBs as the modulator of the neurodegenerative and neuroinflammatory processes is indeed a promising target for the pharmacotherapy of chronic CNS disorders. Resveratrol by affecting the eCBs and NGF with well-documented regulatory actions in the neuroprotective processes and emotional activity might be a valuable therapeutic agent against a wide variety of disorders associated with abnormal eCB or NGF signalling.

Conflict of interest: the authors declare no conflict of interest.

\section{REFERENCES}

1. Tapsell LC, Hemphill I, Cobiac L, Patch CS, Sullivan DR, Fenech M, et al. Health benefits of herbs and spices: the past, the present, the future. Med J Aust 2006; 185: S4-S24. PMD: 17022438.

2. Lastra CA, Villegas I. Resveratrol as an anti-inflammatory and anti-aging agent: mechanism and clinical implications. Mol Nutr Food Res 2005; 49: 405-430. PMD: 17956300.

3. Cal C, Garban H, Jazirehi A, Yeh C, Mizutani Y, Bonavida B. Resveratrol and cancer: chemoprevention, apoptosis, and chemoimmunosensitizing activities. Curr Med ChemAnti-Cancer Agents 2003; 3: 77-93. PMD: 12678904.

4. Hassanzadeh P. Colorectal cancer and NF- $\mathrm{\kappa B}$ signaling pathway. Gastroenterol Hepatol Bed Bench 2011; 4: 127 132. PMD: 24834170.

5. Hung LM, Chen JK, Huang SS, Lee RS, Su MJ. Cardioprotective effect of resveratrol, a natural antioxidant derived from grapes. Cardiovasc Res 2000; 47:549-555. PMD: 10963727.

6. Gulcin I. Antioxidant properties of resveratrol: a structureactivity insight. Innov Food Sci Emerg 2010; 11: 210-218. DOI: 10.1016/j.ifset.2009.07.002.

7. Hassanzadeh P. A quick look at obesity; the enemy within. Gastroenterol Hepatol Bed Bench 2011; 4: 186-191. PMD: 4017438.

8. Patel KR, Scott E, Brown VA, Gescher AJ, Steward WP, Brown K. Clinical trials of resveratrol. Ann NY Acad Sci 2011; 1215: 161-169. DOI: 10.1111/j.17496632.2010.05853.x.

9. Sharma S, Misra CS, Arumugam S, Roy S, Shah V, Davis JA, et al. Antidiabetic activity of resveratrol, a known SIRT1 activator in a genetic model for type-2 diabetes. Phytother Res 2011; 25: 67-73. DOI: 10.1002/ptr.3221. 
10. Okawara M, Katsuki H, Kurimoto E, Shibata H, Kume T, Akaike A. Resveratrol protects dopaminergic neurons in midbrain slice culture from multiple insults. Biochem Pharmacol 2007; 73: 550-560. PMD: 17147953.

11. Sahu SS, Madhyastha S, Rao GM. Neuroprotective effect of resveratrol against prenatal stress induced cognitive impairment and possible involvement of $\mathrm{Na}+, \mathrm{K}+$-ATPase activity. Pharmacol Biochem Behav 2013; 103: 520-525. DOI: 10.1016/j.pbb.2012.09.012.

12. Jung JC, Lim E, Lee Y, Kang JM, Kim H, Jang S, et al. Synthesis of novel trans-stilbene derivatives and evaluation of their potent antioxidant and neuroprotective effects. Eur J Med Chem 2009; 44: 3166-3174. DOI: 10.1016/j.ejmech.2009.03.011.

13. Pangeni R, Sahni JK, Sharma JAS, Baboota S. Resveratrol: review on therapeutic potential and recent advances in drug delivery. Exp Opin Drug Deliv 2014; 11: 1285-1298. DOI: $10.1517 / 17425247.2014 .919253$.

14. Chachay VS, Kirkpatrick CMJ, Hickman IJ, Ferguson M, Prins JB, Martin JH. Resveratrol-Pills to replace a healthy diet? Br J Clin Pharmacol 2011; 72: 27-38. DOI: 10.1111/j.1365-2125.2011.03966.x.

15. Han YS, Zheng WH, Bastianetto S, Chabot JG, Quirion R. Neuroprotective effects of resveratrol against $\beta$-amyloidinduced neurotoxicity in rat hippocampal neurons: Involvement of protein kinase C. Br J Pharmacol 2004; 141: 997-1005. PMD: 15028639.

16. Ferretta A, Gaballo A, Tanzarella P, Capitanio N, Nico $\mathrm{B}$, Annese T, et al. Effect of resveratrol on mitochondrial function: Implications in parkin-associated familiar Parkinson's disease. Biochim Biophys Acta 2014; 1842: 902-915. DOI: 10.1016/j.bbadis.

17. Wang J, Zhang Y, Tang L, Zhang N, Fan D. Protective effects of resveratrol through the up-regulation of SIRT1 expression in the mutant hSOD1-G93A-bearing motor neuronlike cell culture model of amyotrophic lateral sclerosis. Neurosci Lett 2011; 503: 250-255. DOI: 10.1016/j.neulet.2011.08.047.

18. Virmani A, Pinto L, Binienda Z, Ali S. Food, nutrigenomics, and neurodegeneration: neuroprotection by what you eat. Mol Neurobiol 2013; 48: 353-362. DOI: 10.1007/s12035013-8498-3.

19. Ahmeda RF, Abdel-Rahmana RF, Abdallaha HMI, Saleha DO, Farid OAHA, Hessin AF. Antidepressant-like effect of resveratrol in a subchronic model of depression. $J$ Arab Soc Med Res 2014; 9: 48-53. DOI: 10.4103/16874293.145619.
20. Ge JF, Peng L, Cheng JQ, Pan CX, Tang J, Chen FH, et al. Antidepressant-like effect of resveratrol: involvement of antioxidant effect and peripheral regulation on HPA axis. Pharmacol Biochem Behav 2013; 114-115: 64-69. DOI: 10.1016/j.pbb.2013.10.028.

21. Hurley LL, Akinfiresoye L, Kalejaiye O, Tizabi Y. Antidepressant effects of resveratrol in an animal model of depression. Behav Brain Res 2014; 268: 1-7. DOI: 10.1016/j.bbr.2014.03.052.

22. Berton O, Nestler EJ. New approaches to antidepressant drug discovery: Beyond monoamines. Nat Rev Neurosci 2006; 7: 137-151. PMD: 16429123.

23. Castren E, Voikar V, Rantamaki T. Role of neurotrophic factors in depression. Curr Opin Pharmacol 2007; 7: 18-21. PMD: 17049922.

24. Gallo G, Letourneau PC. Localized sources of neurotrophins initiate axon collateral sprouting. J Neurosci 1998; 18: 5403-5414. PMD: 9651222.

25. Lohof AM, Ip NY, Poo MM. Potentiation of developing neuromuscular synapses by the neurotrophins NT-3 and BDNF. Nature 1993; 363: 350-353. PMD: 8497318.

26. Lesser SS, Sherwood NT, Lo DC. Neurotrophins differentially regulate voltage-gated ion channels. Mol Cell Neurosci 1997; 10: 173-183. PMD: 9532579.

27. Hassanzadeh P, Arbabi E. The effects of progesterone on glial cell line-derived neurotrophic factor secretion from C6 glioma cells. Iran J Basic Med Sci 2012, 15: 10461052. PMD: 23493386.

28. Schulte-Herbrüggen O, Jockers-Scherübl MC, Hellweg R. Neurotrophins: from pathophysiology to treatment in Alzheimer's disease. Curr Alzheimer Res 2008; 5: 38-44. PMD: 18288930.

29. Lad SP, Neet KE, Mufson EJ. Nerve growth factor: structure, function and therapeutic implications for Alzheimer's disease. Curr Drug Targets CNS Neurol Disord 2003; 2: 315-334. PMD: 14529363.

30. Aloe L, Rocco ML, Balzamino BO, Micera A. Nerve growth factor: a focus on neuroscience and therapy. Curr Neuropharmacol 2015; 13: 294-303. PMD: 26411962.

31. Hassanzadeh P, Hassanzadeh A. Effects of different psychotropic agents on the central nerve growth factor protein. Iran J Basic Med Sci 2010; 13: 202-209.

32. Hassanzadeh P, Rahimpour S. The cannabinergic system is implicated in the upregulation of central NGF protein by psychotropic drugs. Psychopharmacology 2011; 215: 129-141. DOI: 10.1007/s00213-010-2120-4. 
33. Hassanzadeh P, Hassanzadeh A. Involvement of the neurotrophin and cannabinoid systems in the mechanisms of action of neurokinin receptor antagonists. Eur Neuropsychopharmacol 2011; 21: 905-917. DOI: 10.1016/j.euroneuro.2011.01.002.

34. Hassanzadeh $\mathrm{P}$, Hassanzadeh $\mathrm{A}$. The $\mathrm{CB}_{1}$ receptormediated endocannabinoid signaling and NGF: The novel targets of curcumin. Neurochem Res 2012; 37: 1112-1120. DOI: $10.1007 / \mathrm{s} 11064-012-0716-2$.

35. Hassanzadeh P, Hassanzadeh A. Implication of NGF and endocannabinoid signalling in the mechanism of action of sesamol: a multi-target natural compound with therapeutic potential. Psychopharmacology 2013; 229: 571-578. DOI: 10.1007/s00213-013-3111-z.

36. Hampson AJ, Grimaldi M, Axelrod J, Wink D. Cannabidiol and (-)Delta9-tetrahydrocannabinol are neuroprotective antioxidants. Proc Natl Acad Sci USA 1998; 95: 82688273. PMD: 9653176.

37. Hassanzadeh P, Arbabi E, Atyabi F, Dinarvand R. The endocannabinoid system and NGF are involved in the mechanism of action of resveratrol: A multi-target nutraceutical with therapeutic potential in neuropsychiatric disorders. Psychopharmacology 2015; (in press).

38. Levi-Montalcini R. The nerve growth factor and the neuroscience chess board. Prog Brain Res 2004; 146: 525-527. PMD: 14699984.

39. Triaca V. Homage to Rita Levi-Montalcini. Molecular mechanisms of Alzheimer's disease: NGF modulation of APP processing. Adipobiology 2013; 5: 7-18

40. Fiore M, Chaldakov GN, Aloe L. Nerve growth factor as a signalling molecule for nerve cells and also for the neuroendocrine-immune systems. Rev Neurosci 2009; 20: 133-145. PMD: 19774790.

41. Yanev S, Aloe L, Fiore F, Chaldakov GN. Neurotrophic and metabotrophic potential of nerve growth factor and brainderived neurotrophic factor: Linking cardiometabolic and neuropsychiatric diseases. World J Pharmacol 2013; 2: 92-99. DOI:10.5497/wjp.v2.i4.92

42. Chaldakov GN, Fiore M, Stankulov IS, Manni L, Hristova MG, Antonelli A, et al. Neurotrophin presence in human coronary atherosclerosis and metabolic syndrome: a role for NGF and BDNF in cardiovascular disease? Prog Brain Res 2004; 146: 279-289. PMD: 14699970.

43. Kawamoto K, Matsuda $H$. Nerve growth factor and wound healing. Prog Brain Res 2004; 146: 369-384. . PMD: 14699974.
44. Tuveri MA, Triaca V, Aloe L. The nerve growth factor induces cutaneous ulcer healing in non-responder transplanted skin. Ann Ist Super Sanita 2006; 42: 94-96. PMD: 16801731.

45. Hassanzadeh P. Tissue engineering and growth factors. Updated evidence. Biomed Rev 2012; 23: 19-35. DOI: http://dx.doi.org/10.14748/bmr.v23.26.

46. Kendrick KM. The neurobiology of social bonds. J Neuroendocrinol 2004; 16: 1007-1008. PMD: 15667456.

47. Angelucci F, Aloe L, Vasquez PJ, Mathe AA. Mapping the differences in the brain concentration of brain-derived neurotrophic factor (BDNF) and nerve growth factor (NGF) in an animal model of depression. Neuroreport 2000; 11: 1369-1373. PMD: 10817624.

48. Chaldakov GN, Tonchev A, Aloe L. NGF and BDNF: from nerves to adipose tissue, from neurokines to metabokines. Relevance to neuropsychiatric and cardiometabolic diseases. Riv Psichiatr 2009; 44: 79-87. PMD: 20066808.

49. Alleva E, Petruzzi S, Cirulli F, Aloe L. NGF regulatory role in stress and coping of rodents and humans. Pharmacol Biochem Behav 1996; 54: 65-72. PMD: 8728540.

50. Hellweg R, Lang UE, Nagel M, Baumgartner A. Subchronic treatment with lithium increases nerve growth factor content in distinct brain regions of adult rats. $\mathrm{Mol}$ Psychiatry 2002; 7: 604-608. PMD: 12140783.

51. Cheng S, Ma M, Ma Y, Wang Z, Xu G, Liu X. Combination therapy with intranasal NGF and electroacupuncture enhanced cell proliferation and survival in rats after stroke. Neurol Res 2009; 31: 753-758. doi: 10.1179/174313209X382557.

52. Banasr M, Valentine GW, Li XY, Gourley SL, Taylor JR, Duman RS. Chronic unpredictable stress decreases cell proliferation in the cerebral cortex of the adult rat. Biol Psychiat 2007; 62: 496-504. PMD: 17585885.

53. Miwa T, Moriizumi T, Horikawa I, Uramoto N, Ishimaru $\mathrm{T}$, Nishimura $\mathrm{T}$, et al. Role of nerve growth factor in the olfactory system. Microsc Res Tech 2002; 58: 197-203. PMD: 12203698.

54. Moises HC, Womble MD, Washburn MS, Williams LR. Nerve growth factor facilitates cholinergic neurotransmission between nucleus basalis and the amygdala in rat: an electrophysiological analysis. J Neurosci 1995; 15: 8131-8142. PMD: 8613748.

55. Fernandez-Ruiz JJ, Berrendero F, Herna'ndez ML, Ramos JA. The endogenous cannabinoid system and brain development. Trends Neurosci 2000; 23: 14-20. PMD: 10631784 . 
56. Hassanzadeh $\mathrm{P}$, Hassanzadeh A. Cannabinoid $\mathrm{CB}_{1}$ receptors mediate neurokinin A-induced synaptic plasticity in the spinal locomotor network. J Neurol Neurophysiol 2013; 4: 3. DOI: http://dx.doi.org/10.4172/2155-9562.S1.015.

57. Bambico FR, Duranti A, Tontini A, Tarzia G, Gobbi G. Endocannabinoids in the treatment of mood disorders: evidence from animal models. Curr Pharm Des 2009; 15: 1623-1646. PMD: 19442178.

58. Hassanzadeh $\mathrm{P}$, Rostami F. Cannabinoid $\mathrm{CB}_{1}$ receptors are involved in neuroleptic-induced enhancement of brain neurotensin. Iran J Basic Med Sci 2014; 17: 181-188. PMD: 24847420.

59. Hassanzadeh P, Arbabi E. Cannabinoid CB1 receptors mediate the gastroprotective effect of neurotensin. Iran J Basic Med Sci 2012; 25: 803-810. PMD: 23492756.

60. Williams EJ, Walsh FS, Doherty P. The FGF receptor uses the endocannabinoid signaling system to couple to an axonal growth response. J Cell Biol 2003; 160: 481- 486. PMD: 12578907.

61. Hassanzadeh P. The endocannabinoid system: critical for the neurotrophic action of psychotropic drugs. Biomed Rev 2010; 21: 31-46.

62. Di Marzo V, Melck D, Bisogno T, De Petrocellis L. Endocannabinoids: endogenous cannabinoid receptor ligands with neuroremodulatory action. Trends Neurosci 1998; 21: 521-528. PMD: 9881850.

63. Boger DL, Sato H, Lerner AE, Hedrick MP, Fecik RA, Miyauchi $\mathrm{H}$, et al. Exceptionally potent inhibitors of fatty acid amide hydrolase: the enzyme responsible for degradation of endogenous oleamide and anandamide. Proc Natl Acad Sci USA 2000; 97: 5044-5049. PMD: 10805767.

64. Casanova ML, Blazquez C, Martinez-Palacio J, Villanueva C, Fernandez-Acenero MJ, Huffman JW, et al. Inhibition of skin tumor growth and angiogenesis in vivo by activation of cannabinoid receptors. J Clin Invest 2003; 111: 43-50. PMD: 1251587.

65. Hassanzadeh P, Ahmadiani A. Nitric oxide and c-Jun $\mathrm{N}$-Terminal Kinase are involved in the development of dark neurons induced by inflammatory pain. Synapse 2006; 59: 101-106. doi: 10.1002/syn.20219.

66. Hassanzadeh P. Effect of celecoxib on the peripheral NO production. Iran J Basic Med Sci 2009; 12: 43-50.

67. van der Stelt M, Di Marzo V. Cannabinoid receptors and their role in neuroprotection. Neuromol Med 2005; 7 : 37-50. PMD: 16052037.
68. Hassanzadeh P. Discovery of the endocannabinoid system: A breakthrough in neuroscience. Arch Neurosci 2014; 2: e15030. DOI: 10.5812/archneurosci.15030.

69. Di Marzo V, Hill MP, Bisogno T, Crossman AR, Brotchie JM. Enhanced levels of endogenous cannabinoids in the globus pallidus are associated with a reduction in movement in an animal model of Parkinson's disease. FASEB J 2000; 14: 1432-1438. PMD: 10877836.

70. Gubellini P, Picconi B, Bari M, Battista N, Calabresi $\mathrm{P}$, Centonze D, et al. Experimental parkinsonism alters endocannabinoid degradation: implications for striatal glutamatergic transmission. J Neurosci 2002; 22: 69006907. PMD: 12177188.

71. Lastres-Becker I, De Miguel R, and Fernandez-Ruiz JJ. The endocannabinoid system and Huntigton's disease. Curr Drug Targets CNS Neurol Disord 2003; 2: 335-347. PMD: 18781982.

72. Arevalo-Martin A, Vela JM, Molina-Holgado E, Borrell J, Guaza C. Therapeutic action of cannabinoids in a murine model of multiple sclerosis. J Neurosci. 2003; 23: 2511-2516. PMD: 12684434.

73. Molina-Holgado E, Vela JM, Arévalo-Martín A, A1mazán G, Molina-Holgado F, Borrell J, et al. Cannabinoids promote oligodendrocyte progenitor survival: involvement of cannabinoid receptors and phosphatidylinositol-3 kinase/Akt signaling. J Neurosci 2002; 22: 9742-9753. PMD: 12427829.

74. Garcia-Ovejero D, Arevalo-Martin A, Petrosino S, Docagne $\mathrm{F}$, Hagen $\mathrm{C}$, et al. The endocannabinoid system is modulated in response to spinal cord injury in rats. Neurobiol Dis 2009; 33: 57-71. doi: 10.1016/j. nbd.2008.09.015.

75. McCormick DA, Contreras D. On the cellular and network bases of epileptic seizures. Annu Rev Physiol 2001; 63: 815-846. PMD: 11181977.

76. Hassanzadeh P, Arbabi E, Rostami F. The ameliorative effects of sesamol against seizures, cognitive impairment and oxidative stress in the experimental model of epilepsy. Iran J Basic Med Sci 2014; 17: 100-107. PMD: 2471892.

77. Hassanzadeh P, Arbabi E, Atyabi F, Dinarvand R, Rostami F. Ferulic acid exhibits antiepileptogenic effect and prevents oxidative stress and cognitive impairment in the pentylenetetrazole kindling model of epilepsy in rats. Iran J Basic Med Sci 2015 (in press). 
78. Wallace MJ, Martin BR, De Lorenzo RJ. Evidence for a physiological role of endocannabinoids in the modulation of seizure threshold and severity. Eur J Pharmacol. 2002; 452: 295-301. PMD: 12359270.

79. Hayakawa K, Mishima K, Irie K, Hazekawa M, Mishima S, Fujioka M, et al. Cannabidiol prevents a post-ischemic injury progressively induced by cerebral ischemia via a high-mobility group box1-inhibiting mechanism. Neuropharmacology 2008; 55: 1280-1286. DOI: 10.1016/j.neuropharm.2008.06.040.

80. Weksler ME, Gouras G, Relkin NR, Szabo P. The immune system, amyloid- $\beta$ peptide, and Alzheimer's disease. Immunol Rev 2005; 205: 244-256. PMD: 15882358.

81. Iuvone T, Esposito G, Esposito R, Santamaria R, Di Rosa M, Izzo AA. Neuroprotective effect of cannabidiol, a non-psychoactive component from Cannabis sativa, on beta-amyloid-induced toxicity in PC12 cells. JNeurochem 2004; 89:134-141. PMD: 15030397.

82. Van der Stelt M, Mazzola C, Esposito G, Matial I, Petrosino S, De Filippis D, et al. Endocannabinoids and $\beta$-amyloid-induced neurotoxicity in vivo: effect of pharmacological elevation of endocannabinoid levels. Cell Mol Life Sci 2006; 63:1410-1424. PMD: 16732431.

83. Marsicano G, Goodenough S, Monory K, Hermann H, Eder M, Cannich A, et al. CB1 cannabinoid receptors and on-demand defense against excitotoxicity. Science 2003; 302: 84-88. PMD: 14526074.

84. Hohmann AG, Walker JM. Cannabinoid suppression of noxious heat evoked activity in wide dynamic range neurons in the lumbar dorsal horn of the rat. JNeurophysiol 1999; 81:575-583. PMD: 10036261.

85. GÜhring H, Hamza M, Sergejeva M, Ates M, Kotalla CE, Ledent C. A role for endocannabinoids in indomethacin induced spinal antinociception. Eur J Pharmacol 2002; 454:153-163. PMD:12421642.

86. Welch SP, Eads M. Synergistic interactions of endogenous opioids and cannabinoid systems. Brain Res 1999; 848: 183-190. PMD: 1061271.

87. Hassanzadeh P, Hassanzadeh A. The role of the endocannabinoids in suppression of the HPA axis activity by doxepin. Iran J Basic Med Sci 2011; 14: 414-421. PMD: 23493814.

88. Manji HK, Drevets WC, Charney DS. The cellular neu- robiology of depression. Nat Med 2001; 7: 541-547. PMD: 11329053.

89. Navarro M, Hernandez E, Munoz RM, del Acro I, Villanua MA, Carrera MRA. Acute administration of the CB1 cannabinoid receptor antagonist SR141716A induces anxiety-like responses in the rat. Neuroreport 1997; 8: 491-496. PMD: 9080435.

90. Pirola L, Frojdo S. Resveratrol: one molecule, many targets. IUBMB Life 2008; 60: 323-332. PMD: 18421779.

91. Wang Z, Gu J, Wang X, Xie K, Luan Q, Wan N, et al. Antidepressant-like activity of resveratrol treatment in the forced swim test and tail suspension test in mice: the HPA axis, BDNF expression and phosphorylation of ERK. Pharmacol Biochem Behav 2013; 112: 104-110. DOI: 10.1016/j.pbb.2013.10.007.

92. Xu Y, Wang Z, You W, Zhang X, Li S, Barish PA, et al. Antidepressant-like effect of trans-resveratrol: Involvement of serotonin and noradrenaline system. Eur Neuropsychopharmacol 2010; 20: 405-413. DOI: 10.1016/j.euroneuro.2010.02.013.

93. Hassanzadeh P, Fullwood I, Sothi S, Aldulaimi D. Cancer nanotechnology. Gastroenterol Hepatol Bed Bench 2011; 4: 63-69. PMD: 24834159.

94. Hassanzadeh P. Nanopharmaceurticals: Innovative theranostics for the neurological disorders. Biomed Rev 2014; 25: 25-34.

95. Hassanzadeh P. New perspectives in biosensor technology. Gastroenterol Hepatol Bed Bench 2010; 3: 105-107.

96. Hassanzadeh P, Arbabi E, Rostami F, Atyabi F, Dinarvand R. Carbon nanotubes prolong the regulatory action of nerve growth factor on the endocannabinoid signaling. Physiol Pharmacol 2015; (in press).

97. Hassanzadeh P. Computational modelling: Moonlighting on the neuroscience and medicine. Biomed Rev 2013; 24 : 25-31.

98. Bharali DJ, Siddiqui IA, Adhami VM, Chamcheu JC, Aldahmash AM, Mukhtar H, et al. Nanoparticle delivery of natural products in the prevention and treatment of cancers: current status and future prospects. Cancers 2011; 3: 4024-4045. DOI: 10.3390/cancers3044024.

99. Teskac K, Kristl J. The evidence for solid lipid nanoparticles mediated cell uptake of resveratrol. Int J Pharm 2010; 390: 61-69. DOI: 10.1016/j.ijpharm.2009.10.011. 